\title{
How Gender and Working Conditions Affect Occupational Stress and Job Satisfaction of General Education's Preschool and Elementary Teachers in Greek Public Schools
}

\author{
Michael Galanakis*, Evmorfia Alamani \\ Neapolis University of Pafos, Cyprus, Greece \\ Email: *galanakismichael@hotmail.com
}

How to cite this paper: Galanakis, M., \& Alamani, E. (2020). How Gender and Working Conditions Affect Occupational Stress and Job Satisfaction of General Education's Preschool and Elementary Teachers in Greek Public Schools. Psychology, 11, 364-372. https://doi.org/10.4236/psych.2020.112023

Received: January 24, 2020

Accepted: February 17, 2020

Published: February 20, 2020

Copyright $\odot 2020$ by author(s) and Scientific Research Publishing Inc. This work is licensed under the Creative Commons Attribution International License (CC BY 4.0).

http://creativecommons.org/licenses/by/4.0/

\begin{abstract}
Stress is considered as an accretive psychosocial peril, which has its source in multiple factors and it is considered responsible for many serious diseases. Lately stress appears as a very important and complex problem that needs to be faced both in personal and working relations. There are few researches in Greece concerning teachers' stress and job satisfaction. For that reason, in this particular study, we examined the working conditions' effect on stress and therefore on job satisfaction of 172 Primary and Elementary teachers of General Education in Greek public schools using a relevant weighted questionnaire. In addition, we examined the correlation between gender and occupational stress. The greater purpose of the study was to shed light onto the relation of working conditions to stress and job satisfaction. The t-test showed that stress levels do not differ between the two genders in opposition to our primary hypothesis and previous studies. We used Pearson $r$ coefficient, which did not confirm either the correlation between negative working conditions or the correlation between stress and low job satisfaction and that leads to the need of the matter's further investigation. The fact that gender and working conditions do not affect occupational stress and job satisfaction may be indicative of the need of a more complex approach in understanding these variables.
\end{abstract}

\section{Keywords}

Stress, Working Conditions, Teachers, Gender, Job Satisfaction 


\section{Introduction}

\subsection{Teacher's Stress Definition}

Occupational stress is a modern and complex phenomenon result of a pressing way of life. It is considered as teacher's pressure due to workload and negative working conditions (Amaradidou, 2010).

Stress is defined as an unpleasant emotional state, which many times is related to unpleasant feelings like anger and fear or feelings of imminent danger, tension and worry due to certain threat (Rudow, 2000).

\subsection{Causes of Stress according to Most Prevailing Theories}

According to the Biological theory, the system's protection from stress is particularly important and life maintenance depends a lot on internal stability in front of environmental changes (Fink, 2016). According to Mitrousi, Travlos, Koukia et al. (2013: p. 25) "stress is perceived as a normal reaction of the body, which completely depends on the stimuli degree (in the sense of hyper stimulus and the sensory deprivation)".

In Psychoanalytic theory and according to Freud "stress works" as a "signap" that Ego is threatened and for that reason it has the ability to set in motion the "defense mechanisms" (Mitrousi, Travlos, Koukia at al., 2013: p. 23). In that theory, there are various types of stress, like moral stress caused by Superego and neurotic stress caused by real or not real conflicts with the parents (Mitrousi, Travlos, Koukia at al., 2013).

Finally, according to Cognitive theory and Hoehn-Saric, McLeod \& Freeman (1989), "stress is a global known experience, which operates as a warning mechanism (safety) and transmits warning signs in cases of danger concerning something uncertain" (Mitrousi, Travlos, Koukia at al., 2013: p. 24).

\subsection{Factors That Mark a Stimulus as Stressful}

One of the most important factors that affect stress levels is gender differences. Klassen's (2010) and Antoniou, Polychroni, \& Vlachakis' (2006) research findings show that female teachers have slightly higher occupational stress compared to their male colleagues due to workload and students' behavior in schools of Primary and Elementary Education.

According to Greenglass \& Burke, females' high stress levels may be due to the differences between genders in areas far from work with higher total workload (school and household) and higher conflict degree between work and family roles (Klassen, 2010). O'Laughlin \& Bischoff (2005) found that women reported less support by their partners and greater investment in household and children care compared to men and they feel that workload is disproportioned, which causes even more stress.

\subsection{Stress and Job Satisfaction}

Many teachers experience job satisfaction, but that satisfaction is affected when 
stress hits high levels, because of teaching requirements and students' behavior (Klassen, 2010). Caprara et al. (2006) and Judge, Thoresen, Bono, \& Patton (2001) emphasize that teachers' job satisfaction-according to the prevailing perception of working fulfillment through daily activities-is important (Klassen, 2010). In addition, job satisfaction affects performance, efficiency, commitment, absence, physical and mental health and general well-being of teachers (Klassen, 2010).

According to previous studies occupational stress is a very important variable in teachers' profession and it leads to many negative outcomes affecting the individual and the organization-school. Stress is related to working conditions and is affected by gender. One of the main results of high stress levels is the decrease in job satisfaction levels. The present study tries to examine whether occupational stress levels are affected by gender and working conditions and if job satisfaction is decreased when occupational stress levels increase in Greek Teachers in Elementary Schools. The Greek educational system is somewhat different from other western countries while there is also lack of relevant studies in this field in Greece,

The main purpose of this particular study is to examine the correlation among working conditions, occupational stress and job satisfaction as well as any potential differences in stress levels between men and women.

Our main Hypotheses-Research questions are:

- Men have less occupational stress than women.

- The worse the working conditions the higher the stress the teachers experience.

- The higher the stress the less the job satisfaction the teachers experience.

1) Does gender affect occupational stress?

2) Do working conditions affect occupational stress levels?

3) Is Job satisfaction affected by occupational stress levels?

\section{Method}

\subsection{Sample-Participants}

The sample consists of teachers of general Primary and Elementary Education of public schools in Greece (random sampling). The specific sample was chosen due to the small number of relevant studies concerning Greece. The teachers were permanent staff or substitutes with a stable classroom and frequently attending students.

The location of the sample was: 1) teachers from areas of Xanti, Viotia, Corinth, Heraclio and Rethimno and 2) teachers from various other areas of Greece (online questionnaire). The number of the participants was 172 .

In regards to gender it seems that $130(75.60 \%)$ out of 172 participants of the total sample are female and $42(24.40 \%)$ are male. The males' number is far less, almost $1 / 3$ of the sample, a number almost expected, considering that female teachers are more common in primary and elementary education in 
Greece.

Concerning specialty, regardless of gender, out of the 172 participants 89 $(51.70 \%)$ are elementary teachers, $50(29.10 \%)$ are pre-school teachers and 33 (19.20\%) have stated a different specialty. Among the participants elementary teachers have the higher number, pre-school teachers follow and other specialties come last.

\subsection{Measures}

The measurement tool used is a valid and weighted questionnaire: "Questionnaire for investigating Occupational stress and Job Satisfaction" made by Thanasia E, Kalissiari S, Babalou X.E, Deliha M. \& Karageorgiou A. with the collaboration and support of Medical School of University of Thessaly, the Psychology Department of Aristoteles University of Thessaloniki and KE.P.E.K. of central Greece.

The questionnaire includes 130 questions in six sections. The answers are Likert-type scale graded (5) as following: $0=$ Not at all, $1=$ Very little, $2=$ Moderately, 3 = Enough, $4=$ Too much. There are also a few YES/NO types of questions included.

The first part includes 17 questions about demographic features of participants (gender, age, family status, specialty, education and work type). The second part includes 22 questions about the participants' health (smoking, alcohol, physical discomfort). The third part includes 18 questions about personal well-being (feelings of fatigue and discontent). The fourth part includes 17 questions about working environment (safety and hygiene conditions). The fifth part has 44 questions about working conditions (cooperation and salary) and the sixth part 10 questions concerning the participants' personality.

\subsection{Research Design}

The present study is a cross sectional descriptive quantitative research. The findings were analyzed with the SPSS Vol.25 statistics program using a t-test and two Pearson $r$ correlations. The data is presented in graphs and tables.

\subsection{Procedure}

Questionnaires were given to the teachers in two ways. Online through informative e-mails and some hard-copied in the schools mentioned above after getting each principals' informed consent. During the visit the researchers informed the teachers about the cause and the way of research and they gave explanatory filling instructions. Questionnaires and the consent forms remained at schools for a week and then they were delivered separately to the researchers by the principals. The questionnaires' completion time was approximately 15 minutes. Due to moral and ethics reasons it was made clear to the participants that the questionnaires were anonymous and they could quit at any point. The procedure took place in November 2019. 


\section{Statistical Analysis}

\subsection{Gender, Stress Levels and Job Satisfaction/T-Test}

According to the analysis it seems that the sample distribution is homogenous. And that is shown in the Levene's test. Basic descriptive indicators of the research are presented at this point concerning the number of participants $(\mathrm{N})$, Mean, Std. Deviation and Std. Error Mean. According to the analysis, $130 \mathrm{fe}-$ males and 42 males participated in the research. The occupational stress Mean for females is 60.64 and for males is 61.60 . Analyzing the results of Levene's criteria, which examines the homogeneity of the two groups, we see F $=2901$, Sig > 0.05 and that proves that the two groups show the same distribution variance. Therefore, the Levene test is statistically significant and we examine the values of the T-test's first row.

According to these findings as they appear in the T-test analysis, they show that: $\mathrm{t}(170)=0.541, p>0.05$ so the finding is statistically non-significant. Therefore, we accept the null hypothesis that men and women, virtually experience the same level of occupational stress. Gender does not affect stress levels.

\subsection{Stress, Working Conditions and Job Satisfaction Correlations}

At this point we examine the correlation between working conditions and stress as well as the stress and job satisfaction correlation. For that purpose, two correlation analyses were implemented and the pearson $r$ index was calculated. The findings are presented in two different tables below (Table 1 and Table 2).

Using the Pearson $r$ correlation coefficient and since we have a normal distribution, the level of significance is set out to 0.05 . Table 1 shows that working conditions have a weak positive statistically significant correlation to occupational stress $r=0.128, p<0.05$.

Table 1. Working conditions \& stress descriptive measures.

\begin{tabular}{cccc}
\hline & Mean & Std. Deviation & N \\
\hline Working conditions & 81.5465 & 23.10852 & 172 \\
Stress & 60.8808 & 8.83236 & 172 \\
\hline
\end{tabular}

Table 2. Working conditions \& stress correlation.

\begin{tabular}{|c|c|c|c|}
\hline & & Working conditions & Stress \\
\hline & Pearson Correlation & 1 & $0.128^{*}$ \\
\hline \multirow[t]{3}{*}{ Working conditions } & Sig. (1-tailed) & & 0.047 \\
\hline & $\mathrm{N}$ & 172 & 172 \\
\hline & Pearson Correlation & $0.128^{*}$ & 1 \\
\hline \multirow[t]{2}{*}{ Stress } & Sig. (1-tailed) & 0.047 & \\
\hline & $\mathrm{N}$ & 172 & 172 \\
\hline
\end{tabular}

${ }^{*}$ Correlation is significant at the 0.05 level (1-tailed). 
According to that result we accept the Null Hypothesis $\left(\mathrm{H}_{0}\right)$ : There is no correlation between working conditions and stress $(p>0.05)$.

At this point, using again the Pearson $r$ coefficient and since we have a normal distribution, the level of significance is set out to 0.05 .

Table 3 and Table 4 show the descriptive measures and stress and job satisfaction correlation of 172 teachers. According to the data presented we accept the null hypothesis that there is no correlation between stress and job satisfaction ( $p=0.084, p=0.137$ ). Therefore, we accept the null hypothesis since stress does not correlate with job satisfaction.

\section{Discussion}

This study examined the possible differences in stress levels between male and female teachers of Primary and Elementary General Education in Greece and how working conditions affect stress and job satisfaction. According to the findings: 1 ) male (Mean $=61.60)$ and female teachers experience the same stress levels (Mean $=60.64), \mathrm{t}(170)=0.541, p>0.05 ; 2)$ there is no correlation between working conditions and stress $\mathrm{r}=0.128, p=0.047$ ) and 3) there is no correlation between stress and job satisfaction $\mathrm{r}=0.084, p=0.137$.

So, our first hypothesis that women would have experienced more stress than men was not confirmed and differed from the various previous studies conducted by Klassen (2010) and Antoniou, Polychroni \& Vlachakis (2006) that clearly showed higher stress levels in women than men. If we select to approach stress biologically, maybe women would have been expected to experience higher levels of stress due to endocrinological and physiology reasons (e.g. women have been shown to experience negative emotion in higher intensity and levels) but it seems that the tools used in the present study approach stress and job satisfaction more as a social construct, thus leading to ambiguous results regarding the research hypothesis. Also the fact that the study is based solely on teachers

Table 3. Stress and job satisfaction descriptive measures.

\begin{tabular}{cccc}
\hline & Mean & Std. Deviation & $\mathrm{N}$ \\
\hline Stress & 60.8808 & 8.83236 & 172 \\
Satisfaction & 19.8837 & 11.10705 & 172 \\
\hline
\end{tabular}

Table 4. Stress \& job satisfaction correlation.

\begin{tabular}{cccc}
\hline & & Stress & Satisfaction \\
\hline \multirow{3}{*}{ Stress } & Pearson Correlation & 1 & 0.084 \\
& Sig. (1-tailed) & & 0.137 \\
& $\mathrm{~N}$ & 172 & 172 \\
Satisfaction & Pearson Correlation & 0.084 & 1 \\
& Sig. (1-tailed) & 0.137 & \\
& $\mathrm{~N}$ & 172 & 172 \\
\hline
\end{tabular}


may be explanatory of the results as there seems to be no major role differences for male and female teachers at least in Greece.

Concerning our second hypothesis that difficult working conditions would cause more stress our study showed no correlation between the two factors contrary to Klassen's (2010) findings, which showed that teaching demands and students' behavior increase stress. Moreover, we did not find any correlation between high level stress and low job satisfaction, so our third hypothesis is also not confirmed. Working conditions according to all major stress theories (Karasek, Folkman, Lazarus etc.) are not considered a major stressor. In principal, it is the individual's representation of the working conditions as well as the beliefs and predisposition towards the work itself that may lead to stress. This means that stress is a phenomenon of subjective critical evaluation of one's position. A possible explanation for this finding is that difficult working conditions may not be accredited as such by the teacher and on the other hand other important aspects of the working life may be the crucial factors of stress such as injustice in the working environment, bad interpersonal relationships, lack of autonomy or control and bad management.

Various previous studies noted that higher female stress levels may be caused by the total weight of their obligations in modern society, since their double role as mothers and professionals fills them with more responsibilities. At the same time, they are not accepted in many working environments plus their general place in modern societies burdens them with the stress of success. In the meantime, the teacher profession is regarded in Greece as mainly a women's occupation. This may lead male teachers to experience higher stress levels than in other professions, because of the notion of teacher stereotypically in society norms.

Despite these facts, this study did not show anything relevant, so some certain restraints must be taken under consideration, like the small sample number, the short time in which the research was conducted, its application only in Primary and Elementary Education due to limited access to other ranks and finally the small number of male participants. However, these findings can be a springboard to further investigation of teachers' stress in Greek reality. Also these limitations may help the design of future studies on the same variables but in a larger and more representative sample, leading to further verification or rejection of the present results in our study.

The general observation and acceptance that gender does not affect stress levels in Greek teachers must lead to some improvement steps that must be taken through interventions. Female as well as male teachers should have less job obligations apart from their teaching objectives and they should work during early hours, so they can return to their domestic responsibilities. Finally, their new modern day role in society must be pointed out through speeches and seminars giving relevant information to the public. That would help minimize all the entrenched ideas creating more positive attitudes with acceptance and respect for the working men and women. 
Ultimately, concerning occupational stress and its effect on job satisfaction it should be a priority to the ministry of Labor. They should provide positive working conditions and decent facilities to the teachers regardless of their consequences on stress levels. Nevertheless policies design aiming at the increase of job satisfaction the teaching profession should not aim primarily on stress levels and working conditions but more on other significant factors, like compensation and benefits, safety and purpose to name a few.

Ending the discussion, it should be pointed out that this particular study aims at putting another stone on the scientific studies construction concerning stress and job satisfaction in the educational world. A proposition would be the further examination of the subject in higher educational ranks and different teaching specialties with equal male and female samples. Finally, the studies should be conducted during longer periods of time, so the data of the long-term effect of stress on teachers' job satisfaction will be more accurate.

\section{Conflicts of Interest}

The authors declare no conflicts of interest regarding the publication of this paper.

\section{References}

Amaradidou, S. (2010). Work Burnout and Teachers' Job Satisfaction: A Diachronic Research. https://www.nup.ac.cy/gr/?gclid=EAIaIQobChMIq-6RouzQ5wIVy9DeCh1H4wshEAA YASAAEgIqtfD_BwE

Antoniou, A. S., Polychroni, F., \& Vlachakis, A. N. (2006). Gender and Age Differences in Occupational Stress and Professional Burnout between Primary and High-School Teachers in Greece. Journal of Managerial Psychology, 21, 682-690. https://doi.org/10.1108/02683940610690213

Caprara, G. V., Barbaranelli, C., Steca, P., \& Malone, P. S. (2006). Teachers' Self-Efficacy Beliefs as Determinants of Job Satisfaction and Students' Academic Achievement: A Study at the School Level. Journal of School Psychology, 44, 473-490. https://doi.org/10.1016/j.jsp.2006.09.001

Fink, G. (2016). Stress: Concepts, Definition and History. Neuroscience and Biobehavioral Psychology, 1-9. https://doi.org/10.1016/B978-0-12-809324-5.02208-2

Hoehn-Saric, R., McLeod, D. R., \& Zimmerli, W. D. (1989). Somatic Manifestations in Women with Generalized Anxiety Disorder: Psychophysiological Responses to Psychological Stress. Archives Of General Psychiatry, 46, 1113-1119. https://doi.org/10.1001/archpsyc.1989.01810120055009

Judge, T. A., Thoresen, C. J., Bono, J. E., \& Patton, G. K. (2001). The Job Satisfaction-Job Performance Relationship: A Qualitative and Quantitative Review. Psychological Bulletin, 127, 376-407. https://doi.org/10.1037/0033-2909.127.3.376

Klassen, R. (2010). Teacher Stress: The Mediating Role of Collective Efficacy Beliefs. Journal of Educational Research, 103, 342-350. https://doi.org/10.1080/00220670903383069

Mitrousi, S. Travlos, A., Koukia, E., \& Ziga, S. (2013). Anxiety Theories: A Critical Review. Greek Journal of Nursing Science, 6, 21-27. 
O'Laughlin, E. M., \& Bischoff, L. G. (2005). Balancing Parenthood and Academia: Work/Family Stress as Influenced by Gender and Tenure Status. Journal of Family Issues, 26, 79-106. https://doi.org/10.1177/0192513X04265942

Rudow, B. (2000). Der Arbeits- und Gesundheitsschutz im Lehrerberuf. Gefährdungsbeurteilung der Arbeit von Lehrerinnen und Lehrern. Heddesheim/Baden: Süddeutscher Pädagogischer Verlag. 